\title{
Biomechanical Determinants of Performance and Injury Risk During Cutting: A Performance-Injury Conflict?
}

\author{
Thomas Dos'Santos ${ }^{1,2}\left[\right.$ C Christopher Thomas ${ }^{2} \cdot$ Alistair McBurnie $^{3} \cdot$ Paul Comfort $^{2} \cdot$ Paul A. Jones $^{2}$
}

Accepted: 7 March 2021 / Published online: 3 April 2021

(c) The Author(s) 2021

\begin{abstract}
Background Most cutting biomechanical studies investigate performance and knee joint load determinants independently. This is surprising because cutting is an important action linked to performance and non-contact anterior cruciate ligament (ACL) injuries. The aim of this study was to investigate the relationship between cutting biomechanics and cutting performance (completion time, ground contact time [GCT], exit velocity) and surrogates of non-contact ACL injury risk (knee abduction $[\mathrm{KAM}]$ and internal rotation [KIRM] moments) during $90^{\circ}$ cutting.

Design Mixed, cross-sectional study following an associative design. 61 males from multidirectional sports performed six $90^{\circ}$ pre-planned cutting trials, whereby lower-limb and trunk kinetics and kinematics were evaluated using three-dimensional (3D) motion and ground reaction force analysis over the penultimate (PFC) and final foot contact (FFC). Pearson's and Spearman's correlations were used to explore the relationships between biomechanical variables and cutting performance and injury risk variables. Stepwise regression analysis was also performed.

Results Faster cutting performance was associated $(p \leq 0.05)$ with greater centre of mass $(\mathrm{COM})$ velocities at key instances of the cut ( $r$ or $\rho=0.533-0.752$ ), greater peak and mean propulsive forces ( $r$ or $\rho=0.449-0.651)$, shorter FFC GCTs $(r$ or $\rho=0.569-0.581)$, greater FFC and PFC braking forces $(r=0.430-0.551)$, smaller hip and knee flexion range of motion ( $r$ or $\rho=0.406-0.670)$, greater knee flexion moments (KFMs) $(r=0.482)$, and greater internal foot progression angles $(r=-0.411)$. Stepwise multiple regression analysis revealed that exit velocity, peak resultant propulsive force, PFC mean horizontal braking force, and initial foot progression angle together could explain 64\% $(r=0.801$, adjusted 61.6\%, $p=0.048)$ of the variation in completion time. Greater peak KAMs were associated with greater COM velocities at key instances of the cut ( $r$ or $\rho=-0.491$ to -0.551 ), greater peak knee abduction angles (KAA) $(r=-0.468$ ), and greater FFC braking forces $(r=0.434-0.497)$. Incidentally, faster completion times were associated with greater peak KAMs $(r=-0.412)$ and KIRMs $(r=0.539)$. Stepwise multiple regression analysis revealed that FFC mean vertical braking force and peak KAA together could explain $43 \%$ ( $r=0.652$, adjusted $40.6 \%, p<0.001)$ of the variation peak KAM.

Conclusion Techniques and mechanics associated with faster cutting (i.e. faster COM velocities, greater FFC braking forces in short GCTs, greater KFMs, smaller hip and knee flexion, and greater internal foot progression angles) are in direct conflict with safer cutting mechanics (i.e. reduced knee joint loading, thus ACL injury risk), and support the "performance-injury conflict" concept during cutting. Practitioners should be conscious of this conflict when instructing cutting techniques to optimise performance while minimising knee joint loading, and should, therefore, ensure that their athletes have the physical capacity (i.e. neuromuscular control, co-contraction, and rapid force production) to tolerate and support the knee joint loading during cutting.
\end{abstract}

\section{Introduction}

An athlete's ability to change direction is one of the most important physical qualities for successful performance in multidirectional sports [1-8], and is considered to provide

Thomas Dos'Santos

t.dossantos@mmu.ac.uk

Extended author information available on the last page of the article the mechanical foundation for efficacious agility performance $[3,5,9-11]$. Change of direction (COD) manoeuvres are frequently performed in sports, such as soccer $[4$, 6], netball [1, 12], and rugby [13-15], with soccer players performing $\sim 600$ cuts of $0^{\circ}-90^{\circ}$ [6] during match play, while directional changes of $45^{\circ}$ and $90^{\circ}$ are frequently performed actions in netball [1]. Specifically, side-step cutting actions are the most commonly performed attacking agility action in netball [12], and are typically performed to create separation 


\section{Key Highlights}

Techniques and mechanics associated with faster cutting performance are in direct conflict with safer cutting mechanics (i.e. reduced knee joint loading), and support the "performance-injury conflict" concept that is present during cutting.

Practitioners must be cautious when coaching and manipulating cutting technique and mechanics, and acknowledge the implications of technique modification on performance and potential injury risk.

Practitioners are encouraged to coach penultimate foot contact dominant braking strategies and minimising knee valgus and lateral trunk flexion to facilitate effective performance and potentially reduce knee joint loading.

from an opponent to get into space and receive a pass. Moreover, side-steps are successful evasive manoeuvres in rugby and are linked to positive outcomes such as penetrating the defensive line $[13,14,16]$. As such, developing an athlete's side-step mechanical cutting ability can be considered an important attribute to develop first, particularly from a motor skill learning perspective, before then incorporating unanticipated stimulus within practice drills to better prepare athletes for the chaotic demands of multidirectional sports $[5,9,17,18]$.

Changing direction, particularly side-step manoeuvres, has been identified as a key action associated with noncontact ACL injuries in numerous multidirectional sports (soccer, rugby, handball, netball, Australian rules football, American football, and badminton) [19-28], due to the potential to generate high multiplanar knee joint loading (flexion, rotation, and abduction moments) during the plant foot contact [29-33], thus increasing ACL strain [34-38]. ACL injuries are debilitating and potentially career threatening, with short- and long-term consequences (financial, health, and psychological) [39-43]. Specifically, an elevated and earlier risk of developing osteoarthritis is a primary concern associated with ACL injury [42, 44]. An estimated 2 million ACL injuries occur worldwide [45], most of which typically require surgery [46]; thus, extensive rehabilitation periods are required, resulting in prolonged absence from sport and the potential to lose sporting scholarships or contracts [47]. However, athletes who do successfully return to sport post ACL reconstruction may demonstrate reduced sports-related performance, reduced number of appearances, and shorter career longevity $[48,49]$. Therefore, understanding the mechanics and techniques that can reduce the relative risk of injury during COD actions, while improving performance, are of great interest to researchers and practitioners working with multidirectional athletes.

Despite the importance of directional changes for sports performance and its association with ACL injury risk, it is somewhat surprising that the majority of studies into COD biomechanics investigate performance [50-60] and ACL injury risk surrogate determinants [30, 31, 33, 61-69] independently. From a performance perspective, greater braking and propulsive forces and impulses over short GCTs are related to faster COD speed performance [50, 51, 53-56, 58-60, 70]. Additionally, whole-body kinetics and kinematics such as greater ankle power, ankle plantar-flexor moments, hip power and extensor moments, rapid knee and hip extension, wide lateral foot plants, torso lean and rotation, and low COM are also associated with faster cutting performance $[50,53,70]$; highlighting the importance of the lower-limb triple extensor musculature and trunk lean towards the intended direction of travel. Conversely, from an injury risk perspective, COD techniques with a wide lateral foot plant $[31,33,62,70]$, greater hip abduction angles $[52,68]$, increased initial foot progression angles [61, 68], increased initial hip internal rotation angles $[63,64,68,70]$, greater peak and initial KAA [33, 61-64], greater lateral trunk flexion [31, 62, 67, 71, 72], smaller knee flexion angles $[52,73]$, and greater ground reaction forces (GRF) [30, 63, $68]$ are associated with greater peak KAMs and thus greater ACL strain [35, 74-77]. However, less is known regarding the mechanics and techniques necessary for optimal COD performance and how they relate and interact with injury risk $[70,78,79]$.

There is preliminary evidence, although limited, which indicates the techniques and mechanics required for faster COD performance are in direct conflict with the techniques and mechanics required for safer COD (i.e. lower knee joint loads) [70, 78-81]. For instance, COD techniques such as increased IFPAs and pelvic and hip internal rotation angles are associated with greater KAMs [31, 61, 68], but may be optimal for COD performance due to effective realignment of the whole-body COM into the new intended direction $[61,82]$. Extended knee postures (i.e. smaller knee flexion) increase anterior tibial shear and subsequently strains the ACL [74, 83-87], yet increasing knee flexion during side-stepping increases GCT and reduces exit velocity [80], thus negatively affecting performance. Greater KFMs [70] and posterior GRF $[57,58,88]$ are associated with faster COD performance, but can also increase proximal anterior tibial shear [87, 89] and potential ACL loading [74, 83-85]. Lateral trunk flexion has been shown to increase knee joint loading [31, 32, 62]; however, this strategy may be adopted by athletes to deceive (feint) opponents [90-92]. Wide lateral foot plants [31-33, 62, 70] are also associated with greater KAMs, where larger moment arms and KAMs are created with a more medial whole-body position with 
respect to the foot and centre of pressure positioning more lateral to the COM of the body and tibia $[61,70]$. However, a wide lateral foot plant is required for medial-lateral GRF and impulse generation to accelerate into the new direction $[53,62,70,93]$.

To the authors best knowledge, Havens and Sigward [70], Sankey et al. [79], and McBurnie et al. [81] are the only researchers to investigate the biomechanical determinants of cutting performance and surrogates of ACL injury risk, confirming that techniques required for faster performance are in direct conflict with reduced knee joint loading. For example, Havens and Sigward [70] revealed faster cutting performance was associated with greater lateral foot plant distances, medial-lateral impulse, and internal hip rotation angles, though it is worth noting that greater KAMs were also observed with wider lateral foot plants, which may increase ACL injury risk. Additionally, Sankey et al. [79] found increases in sagittal triple acceleration, frontal plane hip acceleration and transverse plane hip acceleration were related to sharper COD angles, while sagittal triple acceleration also related to greater medial COM acceleration; however, the aforementioned variables were also associated with greater KAMs. McBurnie et al. [81] observed greater peak KAMs and KIRMs were demonstrated by athletes who demonstrated faster cutting completion times, greater horizontal approach velocities, and greater peak hip flexion moments. Moreover, a recent review by Fox [78] has highlighted that reducing "high-risk" postures (such as wide foot plants, lateral trunk flexion, increasing knee flexion, internal hip and foot progression angle) are viable strategies to reduce such knee joint loads, but could be to the detriment of faster performance. As athletes are driven by performance, they may be unlikely to adopt movement strategies which decrease knee injury risk if they do not result in effective performance [70, 78]. Collectively, these studies suggest that there is a "performance-injury conflict" during COD, which is problematic for practitioners who aim to improve their athletes' performance and reduce injury risk. As such, further insight is required to improve our understanding of mechanics required for faster and safer COD.

Although previous work has indeed provided further insight into the performance and injury risk determinants during cutting [70, 79], McBurnie et al. [81] is the only study to consider KIRMs while also examining PFC braking characteristics. This is important because ACL strain is amplified when a combination of high frontal and transverse knee moments are generated in comparison to uniplanar loading [34-38], and emerging research has demonstrated that greater braking forces displayed during the PFC (i.e. PFC dominant braking) is associated with faster COD performance $[57,58,88,94]$ and reduced KAMs in the FFC [30, 61, 62]. Havens and Sigward [70] did not examine approach or exit velocities during the COD which is a notable absence because faster approach velocities and minimising velocity loss during cutting has been identified as a key determinant of faster performance $[57,95,96]$, and faster approach velocities concurrently elevate knee joint loading [97-101]. Finally, only a limited number of studies have examined the whole-body biomechanical determinants of COD performance using 3D motion analysis [50, 53, 56, 70, 79, 81], but these studies are low in sample size $(n=15-34)$. Therefore, the aim of this study was to expand on previous work $[70,79,81]$, by investigating the relationship between cutting biomechanics and cutting performance and surrogates of non-contact ACL injury risk (i.e. KAMs and KIRMs) during $90^{\circ}$ cutting with a larger sample size, using a preplanned cutting task containing a longer approach distance and higher entry velocity. Research has shown COD biomechanics are velocity dependent [33,97-101], and athletes in multidirectional sport perform high-entry velocity CODs from long approach distances [1, 10, 102]. Conducting such research into the relationship and interaction between performance and injury risk determinants during COD, may assist in the development of more effective ACL injury mitigation and COD speed programmes [78]. It was hypothesised that the mechanical properties responsible for faster performance would concurrently increase knee joint loading.

\section{Methods}

\subsection{Research Design}

This study used a cross-sectional design to determine the relationship between COD biomechanics and COD performance (completion time, GCT, exit velocity) and injury risk (peak KAMs and peak KIRMs), following an associative strategy [103]. Participants performed six $90^{\circ}$ cuts (Fig. 1) from their right limb and 3D motion and GRF analysis was used to explore the joint kinetic, kinematic, and GRF determinants of performance and injury risk during cutting, similar to the methodological procedures of previous research $[70,104,105]$.

\subsection{Participants}

A minimum sample size of 48 participants was determined from an a priori power analysis using $\mathrm{G}^{*}$ Power (Version 3.1, University of Dusseldorf, Germany) [106]. This was based upon a previously reported correlation value of 0.472 (lateral foot plant distance to peak KAM) [70], a power of 0.95 , and $\alpha$ level of 0.05 . Lateral foot plant distance theoretically should be a key variable linked to the performance-injury conflict, because of the requirement to generate mediolateral impulse [53, 62, 70, 93] for faster performance, and the increased moment arm distance between the GRF 


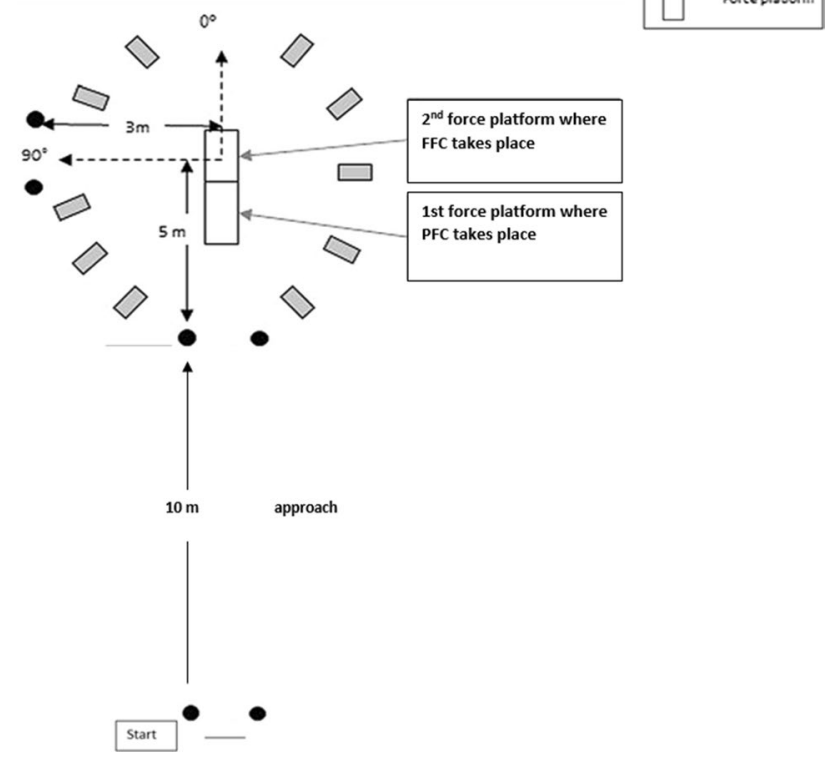

Fig. 1 Schematic representations of the $90^{\circ}$ cutting task

vector and knee joint centre increasing peak KAMs, thus ACL injury risk [31-33, 62, 70]. As such, 61 male athletes (mean \pm SD; age: $20.7 \pm 3.8$ years, height: $1.77 \pm 0.06 \mathrm{~m}$, mass: $74.7 \pm 10.0 \mathrm{~kg}$ ) from multiple sports ( $\operatorname{soccer} n=43$, rugby $n=10$, cricket $n=7$, field hockey $n=1$ ) participated in this study. For inclusion in the study, all athletes had played their respective sport for a minimum of 5 years and regularly performed one game and two structured skill-based sessions per week. All athletes were free from injury during the study and none of the athletes had suffered a prior traumatic knee injury such as an ACL injury. At the time of testing, players were currently in-season (competition phase). The investigation was approved by the Institutional Ethics Review Board (HSR1617-02), and all participants were informed of the benefits and risks of the investigation prior to signing institutionally approved consent or parental assent documents to participate in the study.

\subsection{Procedures}

The warm-up [104], marker placement [30, 104, 105, 107], $3 \mathrm{D}$ motion analysis [30, 104, 105, 107], and procedures were based on previously published methodologies [81, $104,105,107]$; thus, a brief overview is provided here. Each participant performed six acceptable trials of a $90^{\circ}$ pre-planned side-step cut (Fig. 1) as fast as possible and were provided with standardised footwear to control for shoe-surface interface (Balance W490, New Balance, Boston, MA, USA). Completion time was assessed using two sets of Brower timing lights placed at hip height at the start and finish (Draper, UT, USA). Marker and force data were collected over the PFC and FFC using ten Qualisys Oqus 7 (Gothenburg, Sweden) infrared cameras $(240 \mathrm{~Hz})$ operating through Qualisys Track Manager software (Qualisys, version 2.16 (Build 3520), Gothenburg, Sweden) and GRFs were collected from two $600 \mathrm{~mm} \times 900 \mathrm{~mm}$ AMTI (Advanced Mechanical Technology, Inc, Watertown, MA, USA) force platforms (Model number: 600900) embedded into the running track sampling at $1200 \mathrm{~Hz}$. Using the pipeline function in visual $3 \mathrm{D}$, joint coordinate (marker) and force data were smoothed using a Butterworth low-pass digital filter with cut-off frequencies of 15 and $25 \mathrm{~Hz}$, based on a priori residual analysis [108], visual inspection of motion data, recommendations by Roewer et al. [109], and to preserve the GRF signal to explore kinetic determinants. Additionally, we have previously reported good agreements $(\rho=0.768-0.859)$ for peak KAM participant ranking between 15 and $25 \mathrm{~Hz}$ and matched cut-off frequencies $(12-12 \mathrm{~Hz}, 15-15 \mathrm{~Hz}$, 18-18 Hz) [110]; thus, participants were likely to display similar rankings between conditions. Lower limb joint moments were calculated using an inverse dynamics approach [111] through Visual 3D software (C-motion, version 6.01.12, Germantown, USA) and were defined as external moments and normalised to body mass. Joint kinematics and GRF were also calculated using visual 3D, while GRF braking and propulsive characteristics were normalised relative to body weight, with vertical, anterior-posterior, and medial-lateral corresponding to Fz, Fx, and Fy, respectively.

\subsection{Kinetic and Kinematic Variables}

A full description of variables along with definitions, abbreviations, and calculations are provided in Supplementary Material 1. Briefly, lower-limb joint moments were calculated over the FFC and lower-limb joint and trunk angles were also calculated and assessed at initial contact, peak, and range of motion of the FFC. Peak and mean GRF braking and propulsive characteristics were also calculated. Weight acceptance (braking) was defined as the point of initial contact to maximum knee flexion and push-off (propulsion) was defined the point of maximum knee flexion to toe-off. PFC braking forces were also assessed for an indication of braking strategies, and horizontal COM velocity profiles at PFC touch-down to determine approach velocity, FFC touch-down, and FFC toe-off to determine exit velocity (Supplementary Material 1) were also examined. COD performance dependent variables were completion time, FFC GCT, and exit velocity, while injury risk dependent variables were peak KAMs and peak KIRMs and were used as surrogates of ACL injury risk [31, 32]. 


\subsection{Statistical Analyses}

All statistical analyses were performed in SPSS v 25 (SPSS Inc., Chicago, IL, USA) and Microsoft Excel (version 2016, Microsoft Corp., Redmond, WA, USA). Normality was inspected for all variables using a Shapiro-Wilks test. To explore the biomechanical determinants of performance and injury risk-dependent variables, Pearson's (for parametric data) and Spearman's (for non-parametric data) correlations were used, similar to previous research $[60,70]$. Correlations were evaluated as follows: trivial $(0.00-0.09)$, small $(0.10-0.29)$, moderate $(0.30-0.49)$, large $(0.50-0.69)$, very large (0.70-0.89), nearly perfect (0.90-0.99), and perfect (1.00) [112]. A correlation cut-off value of $\geq 0.40$ was considered relevant according to Welch et al. [51] who also investigated the biomechanical determinants of cutting performance. Thus, correlations greater than this value are only reported. Stepwise multiple regression analysis was also performed to explore the relationship between the abovementioned variables and key primary performance and injury risk variables. Only significantly correlated variables that were parametric were considered for the Stepwise multiple regression analysis, and no more than 6 variables were inputted into the model to ensure a minimum 10:1 participant to independent variable ratio was present [113]. Statistical significance was defined as $p \leq 0.05$ for all tests. A minimum of four trials was used for each participant [61], and an average of individual trial peaks for each variable was used [104, 114].

\section{Results}

Descriptive statistics are presented in Table 1 for cutting variables. Pearson's and Spearman's correlation values between COD biomechanical variables and cut completion times, GCT, exit velocity, peak KAM, and peak KIRM are presented in Supplementary material 2. FFC GCT and peak KIRM were non-parametric; thus, Stepwise regression analysis could not be performed.

\subsection{Completion Times Correlations}

Shorter completion times were significantly $(p \leq 0.001)$ and very largely associated with greater FFC touch-down $(\rho=-0.752)$ (Fig. 2) and exit velocities ( $r=-0.733$ ); largely associated with faster approach velocities $(\rho=-0.660)$, greater peak $(r=-0.641)$ (Fig. 2) and mean resultant propulsive forces $(r=-0.530)$ and medial-lateral propulsive forces $(r=-0.588$ to -0.627$)$, shorter approach times $(\rho=0.620)$, greater mean horizontal propulsive forces $(r=0.608)$, greater peak KIRMs $(\rho=-0.539)$, shorter PFC and FFC GCTs $(\rho=0.551-0.581)$, and greater
PFC ( $r=0.551)$ and FFC mean horizontal braking forces $(r=0.535)$; and moderately associated with greater mean FFC resultant braking forces $(r=-0.484)$, greater peak vertical propulsive forces $(r=-0.449)$ and horizontal propulsive forces $(r=-0.460)$, greater peak KAMs $(r=-0.412)$, greater initial foot progression angles $(r=-0.411)$, and lower hip flexion range of motion $(r=0.406)$. Stepwise multiple regression analysis revealed that greater exit velocities, greater peak resultant propulsive forces, greater PFC mean horizontal braking forces, and greater initial foot progression angles together could explain $64.2 \%(r=0.801$, adjusted $61.6 \%, p=0.048)$ of the variation in completion time. The regression equation is presented in Table 2.

\subsection{FFC GCT Correlations}

Shorter GCTs were significantly $(p \leq 0.001)$ and largely associated with greater lateral foot plant distances $(\rho=0.626)$, lower peak knee and hip flexion angles and range of motion $(\rho=0.603-0.670)$ (Fig. 2), and lower peak lateral trunk flexion angles and range of motion $(\rho=0.595-0.623)$.

\subsection{Exit Velocity Correlations}

Faster exit velocities were significantly $(p \leq 0.001)$ and very largely associated with shorter completion times $(r=-0.733)$ and greater FFC touch-down velocities $(\rho=0.725)$; largely associated with greater mean and peak medial-lateral $(r=0.638-0.651)$ and resultant propulsive forces $(r=0.549-0.568)$, shorter FFC GCTs $(\rho=-0.569)$, greater peak vertical $(r=0.540)$ and horizontal propulsive forces $(r=0.500)$, and greater approach velocities $(\rho=0.533)$; and moderately associated with greater mean vertical propulsive forces $(r=0.499)$, shorter PFC GCTs $(\rho=-0.484)$, greater peak KFMs $(r=0.482)$, lower hip flexion range of motion $(\rho=0.470)$, greater FFC mean vertical braking forces $(r=0.456)$, and greater PFC mean horizontal braking forces $(r=-0.430)$. Stepwise multiple regression analysis revealed that greater FFC peak medial-lateral propulsive forces and peak greater KFMs together could explain $47.8 \%$ ( $r=0.690$, adjusted $45.7 \%, p=0.019)$ of the variation in exit velocity. The regression equation is presented in Table 2.

\subsection{Peak KAMs Correlations}

Greater peak KAMs were significantly $(p \leq 0.001)$ and largely associated with greater peak KIRMs $(\rho=-0.557)$ (Fig. 2); and moderately associated with greater FFC touchdown velocities $(\rho=-0.491)$ (Fig. 2), greater peak KAAs $(r=-0.468)$ (Fig. 2), greater FFC mean vertical, horizontal, and resultant braking forces $(r=0.434-0.497)$, and shorter completion times $(r=-0.412)$. Stepwise multiple regression 


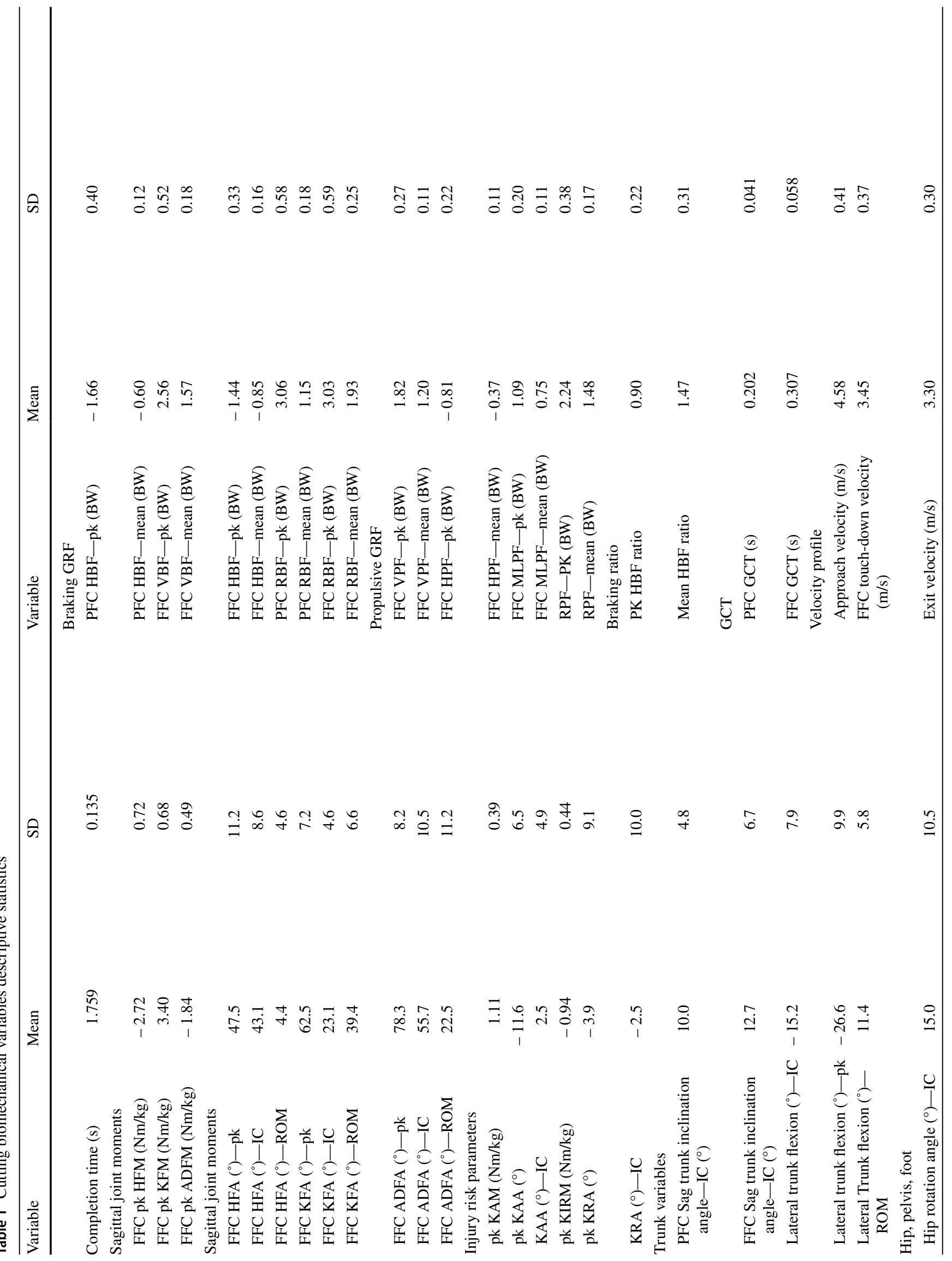




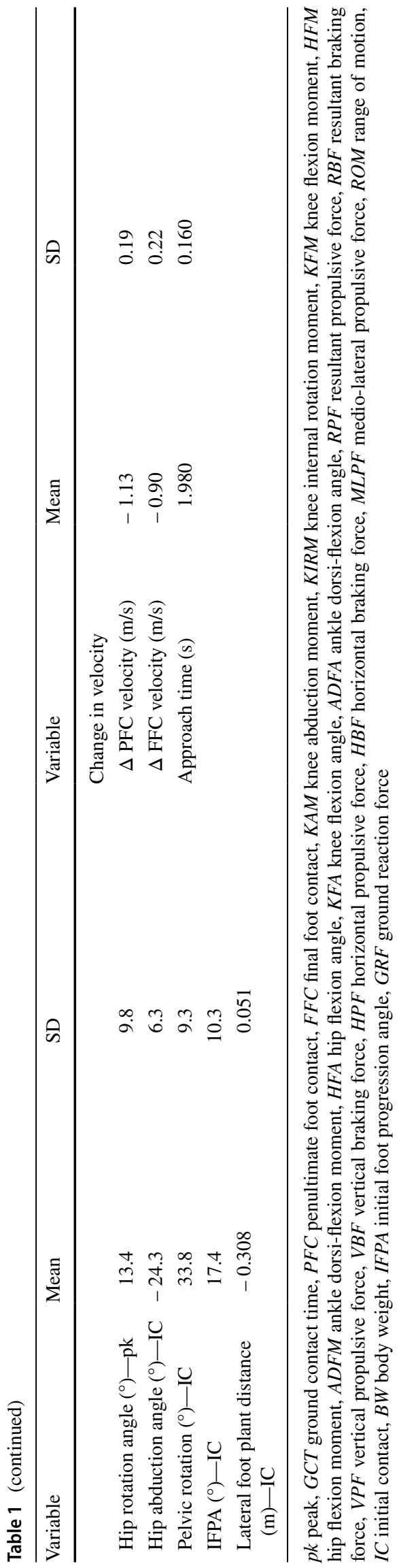

analysis revealed that greater FFC mean vertical braking forces and greater peak KAA together could explain $42.6 \%$ ( $r=0.652$, adjusted $40.6 \%, p<0.001)$ of the variation peak KAM. The regression equation is presented in Table 2.

\subsection{Peak KIRM correlations}

Greater peak KIRMs were significantly $(p \leq 0.001)$ and largely associated with greater peak KAMs $(\rho=-0.557)$, greater FFC touch-down velocities $(\rho=-0.551)$, shorter completion times $(\rho=0.539)$, greater approach velocities $(\rho=-0.534)$, and greater FFC peak resultant braking forces $(\rho=-0.505)$; and moderately associated with greater FFC mean $(\rho=-0.468)$ and peak vertical braking forces $(\rho=-0.475)$, and greater FFC peak resultant braking forces $(\rho=-0.458)$.

\section{Discussion}

The aim of this study was to expand on the work of previous research $[70,79,81]$ by investigating the relationship between cutting biomechanics and cutting performance and surrogates of non-contact ACL injury risk during a long cutting task, in a large sample size. The results of this study substantiate previous work $[70,79,81]$ and the study hypothesis, whereby techniques and mechanics associated with faster performance (i.e. faster cutting COM velocities, greater FFC braking forces in short GCTs, greater KFMs, smaller hip and knee flexion, and greater internal foot progression angles) are in direct conflict with safer COD mechanics (i.e. reduced knee joint loading) (Table 2, Fig. 2), and support the concept that a "performance-injury conflict" exists during cutting [78-80, 101].

From a performance perspective, stepwise multiple regression analysis revealed that greater exit velocity, greater peak resultant propulsive forces, greater PFC mean horizontal braking force, and greater initial foot progression angle together could explain $64.2 \%(r=0.801$, adjusted $61.6 \%, p=0.048$ ) of the variation in cutting completion time (Table 2). Greater exit velocities permit athletes to cover greater horizontal displacements over shorter times, while greater resultant propulsive forces increase impulse which, based on the impulse-momentum relationship, leads to greater changes in momentum, thus velocity $[115,116]$. Therefore, it is unsurprising that the two aforementioned variables were strong determinants of cutting performance. Additionally, cutting is a multistep action [30, 98, 117-119] and displaying greater braking forces in a posteriorly directed direction facilitates reductions in momentum (net deceleration) to permit effective braking [94], thus rationalising the importance of PFC horizontal braking forces for faster cutting performance. Finally, greater internally rotated 
Fig. 2 Correlations between change of direction biomechanical variables and performance and injury risk variables. a Completion time and FFC touch-down velocity; b completion time and peak RPF; c GCT and knee flexion ROM; $\mathbf{d}$ peak KAM and FFC touch-down velocity; e peak KAM and Peak KIRM; f peak KAM and PEAK KA
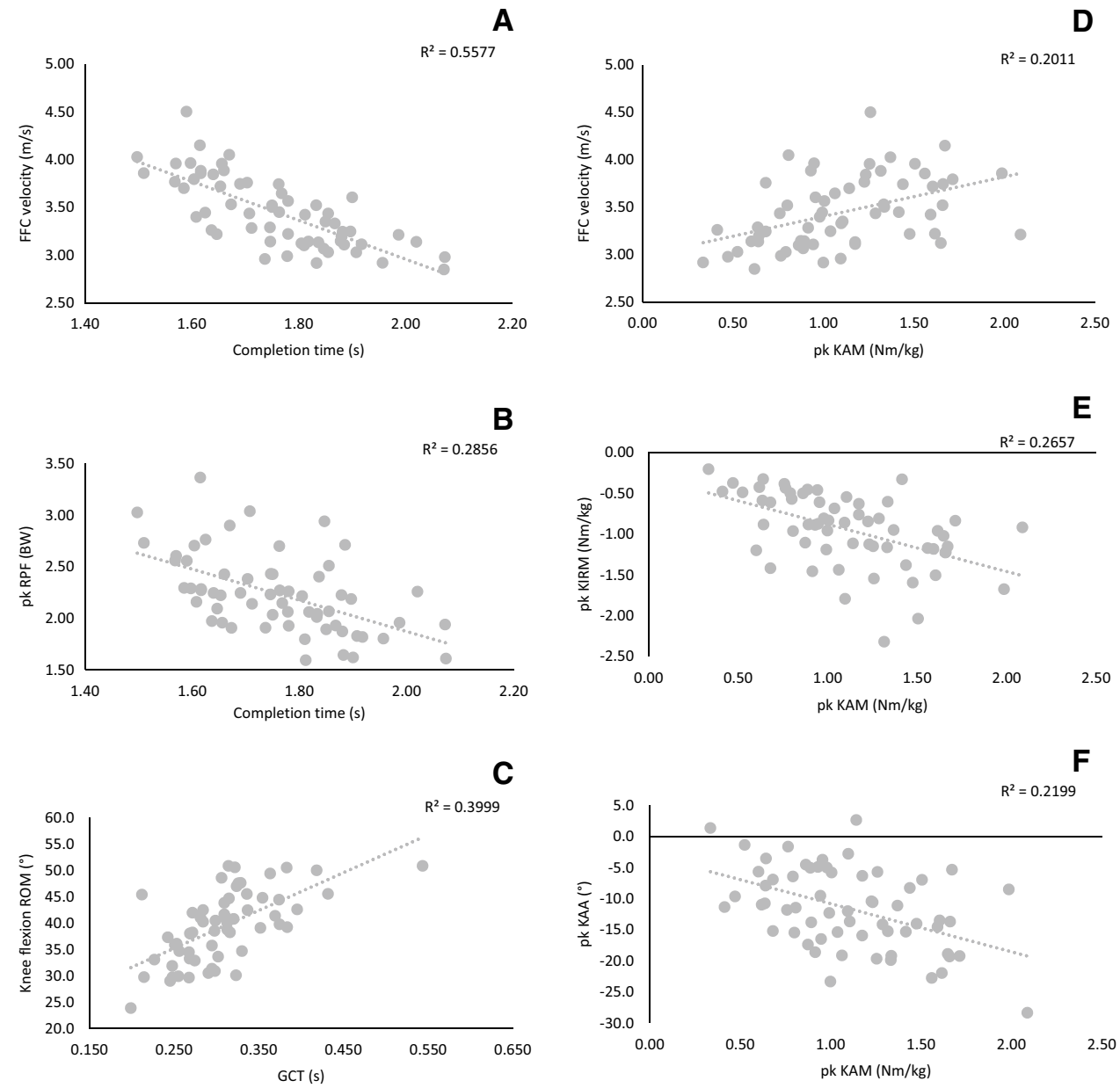

Table 2 Stepwise multiple regression predictors for completion time, exit velocity and peak KAMs

\begin{tabular}{|c|c|c|c|c|c|c|c|c|c|}
\hline Block & Variable & $r$ & $r^{2}(\%)$ & Adjusted $r^{2}(\%)$ & $r^{2}$ change $(\%)$ & Adjusted $r^{2}$ change (\%) & $B$ & Standard error $\beta$ & $\beta$ \\
\hline \multicolumn{10}{|c|}{ Completion time predictors } \\
\hline 1 & Exit velocity & 0.733 & $0.538(53.8)$ & $0.530(53.0)$ & $0.538(53.8)$ & $0.530(53.0)$ & -0.237 & 0.045 & $-0.536 * *$ \\
\hline 2 & FFC peak RPF & 0.746 & $0.557(55.7)$ & $0.541(54.1)$ & $0.019(1.9)$ & $0.012(1.2)$ & -0.022 & 0.036 & $-0.062 *$ \\
\hline 3 & PFC mean $\mathrm{HBF}$ & 0.785 & $0.616(61.6)$ & $0.595(59.5)$ & $0.059(5.9)$ & $0.054(5.4)$ & 0.305 & 0.106 & $0.260 *$ \\
\hline 4 & IFPA & 0.801 & $0.642(64.2)$ & $0.616(61.6)$ & $0.026(2.6)$ & $0.021(2.1)$ & -0.002 & 0.001 & $-0.177 *$ \\
\hline \multicolumn{10}{|c|}{ Exit velocity predictors } \\
\hline 1 & FFC peak MLPF & 0.651 & $0.432(42.3)$ & $0.413(41.3)$ & $0.432(42.3)$ & $0.413(41.3)$ & 0.683 & 0.179 & $0.440 * *$ \\
\hline 2 & FFC KFM & 0.690 & $0.478(47.8)$ & $0.457(45.7)$ & $0.052(5.2)$ & $0.044(4.4)$ & 0.114 & 0.050 & $0.225^{*}$ \\
\hline \multicolumn{10}{|c|}{ Peak KAM predictors } \\
\hline 1 & FFC mean VBF & 0.497 & $0.247(24.7)$ & $0.234(23.4)$ & $0.247(24.7)$ & $0.234(23.4)$ & 1.017 & 0.222 & $0.457 * *$ \\
\hline 2 & FFC peak KAA & 0.652 & $0.426(42.6)$ & $0.406(40.6)$ & 0.179 (17.9) & $0.172(17.2)$ & -0.026 & 0.006 & $-0.425 * *$ \\
\hline
\end{tabular}

$F F C$ final foot contact, $M L P F$ medio-lateral propulsive force, $K F M$ knee flexion moment, $V B F$ vertical braking force, $H B F$ horizontal braking force, $P F C$ penultimate foot contact, $K A A$ knee abduction angle, IFPA initial foot progression angle, $R P F$ resultant propulsive force

$* * p<0.001 ; * p<0.05$

foot postures reduce the redirection requirements during the COD by more effectively aligning the whole-body COM towards the intended direction of travel [70, 82, 120]. Consequently, these findings highlight that faster $90^{\circ}$ cutting performance is underpinned by the interactions between velocity, propulsion, braking, and technique.

To our best knowledge, only three studies have concurrently investigated COD performance and injury risk 
biomechanical determinants [70, 79, 81]; however, based on these studies and biomechanical principles, mechanics and techniques required for safer cutting performance, thus injury mitigation, are at odds with performance [70, 78-80, 101]. The "performance-injury conflict" is problematic because athletes are unlikely to adopt safer strategies at the expense of faster performance [70]. The results of the current study support the limited research $[70,78-81]$ and the concept of a "performance-injury conflict" [70, 78-80, 101], whereby techniques and mechanics associated with faster performance (i.e. faster PFC and FFC velocity, greater FFC braking forces over short GCTs, greater KFMs, smaller hip and knee flexion, and greater internal foot progression angles) are in direct conflict with safer COD mechanics (i.e. reduced knee joint loading) (Fig. 2). This issue is problematic for practitioners and athletes who want to adopt cutting strategies that maximise performance while concurrently minimising injury risk. For example, greater COM approach velocities and velocity over key instances of the PFC and FFC were associated with cutting faster performance and greater knee joint loads. Instructing athletes to perform COD actions slowly is not a viable strategy $[78,101]$, given its importance for faster performance [57, 81, 95, 96]. As such, practitioners must acknowledge that increased knee joint loads are typically associated with greater approach and COD velocity profiles, and should, therefore, progress COD velocity progressively and cautiously with their athletes [101].

Supporting previous work [70, 81], greater peak KFMs were associated with faster cutting performance; likely a product of the faster approach velocities and braking forces. Greater frontal and transverse knee joint loads were moderate to largely associated with greater COM approach velocities, and greater velocity profiles over key instances of the PFC and FFC. These findings support the concept that approach velocity is a key factor regulating cutting knee joint loads [33, 80, 81, 97, 98, 100, 101]. In addition, higher impact braking forces over shorter GCTs were moderate to largely associated with faster performance. Conversely, lower braking forces over longer GCTs were characteristics associated with lower knee joint loads but slower performance. Greater KFMs and posterior GRFs are also associated proximal anterior tibial shear $[87,89]$ and potential ACL loading [74, 83-85], but are also associated with faster cutting performance $[17,70,81]$; highlighting the conflict between performance and injury risk. Again, braking forces and GCT are influenced by an athlete's approach velocity and therefore, given its importance for performance, lowering braking forces and increasing GCT duration are not advisable strategies for coaches to implement with their athletes, but they should acknowledge this conflict when coaching cutting.
From a cutting technical perspective, sagittal plane lowerlimb kinematics have an important role for performance and injury risk $[78,79]$. For example, athletes in the present study who demonstrated faster performance yet greater knee joint loads, demonstrated smaller FFC hip and knee flexion and thus, arguably a "stiffer" hip and knee strategy. This result supports previous work that found increasing knee flexion during cutting concurrently reduced braking GRFs and peak KFMs [80], but negatively impacted performance by increasing GCT and reducing exit velocity. Celebrini et al. [73] found increasing knee flexion reduced KAMs during cutting, while Welch et al. [53] has reported resisting hip flexion over weight acceptance was associated with faster cutting performance. In the transverse plane, greater initial foot progression angles were moderately associated with faster cutting performance and previous work has shown strong relationships between initial foot progression angles and peak KAMs [61, 68], indicating a potential trade-off between performance and injury risk.

A stiffer (i.e. reduced range of motion) hip and knee strategy is effective for performance by reducing GCT and potentially permitting more effective reactive strength and stretch shortening cycle utilisation $[53,121,122]$, thus facilitating more effective force transmission due to the rapid transition from braking to push-off. However, stiffer and extended braking strategies ineffectively dissipates forces and energy [80, 123-127], increases loading rates [128], and may increase anterior tibial [74, 83-85] and knee abductor loading [128-131]. Soft weight acceptance strategies are often coached in injury mitigation programmes to reduce impact GRFs and knee joint loads [73, 132-134]; however, practitioners must consider the conflict between performance and injury risk when manipulating such sagittal plane joint kinematics during cutting. Because ACL injuries occur $\leq 50 \mathrm{~ms}$ at extended knee postures with minimal hip flexion [26, 135], encouraging greater initially flexed postures with rapid hip and knee co-flexion could be a safer cutting strategy [136], but could be disadvantageous to performance and thus, practitioners should be conscious of this conflict when manipulating sagittal plane mechanics.

Of concern, large relationships were observed between peak KAMs and KIRMs (Fig. 2). This finding is problematic because ACL strain is amplified when a combination of high frontal and transverse knee moments are generated in combination with anterior tibial shear, compared to uniplanar loading [34-38]. The majority of investigations that have investigated the biomechanical determinants of injury risk during COD have primarily focused on KAMs [30, 31, 33, $61-64,66-71,79]$, with only a limited number of studies investigating KIRMs [31, 52, 67, 71, 81]. The results from this study show a large relationship between the peak KAMs and KIRMs; however, greater FFC touch-down velocities and mean vertical braking forces were the only two variables 
to be moderately related to both peak KAMs and KIRMs. Therefore, it is likely that participants with high frontal knee loads are "worse-off" performers, who also incur high transverse knee loads.

Although several variables have been identified as factors linked to faster performance and greater knee joint loads, some variables have been shown to be associated with faster performance and lower knee joint loads, or offer no associated performance detriments or hazardous increases in knee joint loads (Supplementary Material 2). For example, greater peak KAAs were moderately associated with greater peak KAMs, corroborating previous research [33, 61-64], while no associated performance benefits were found in terms of KAA and cutting performance, which is in line previous research [50]. Increased KAAs have the effect of placing the knee more medial to the resultant GRF vector and, thus, increase the lever arm of the resultant GRF vector relative to the knee joint, leading to an increased KAM [62]. Additionally, increases in knee valgus angle of $2^{\circ}$ can lead to a $40 \mathrm{Nm}$ change in knee valgus moment [137], while prospective research reported greater valgus angles were associated with increased risk of non-contact ACL injury [77]. As such, reducing KAAs during cutting appears to be viable strategy to reduce knee joint loading, thus ACL injury risk, with no associated cutting performance detriments.

Greater PFC mean horizontal braking forces were largely associated with faster cutting performance, and previous research that has found greater PFC braking forces and PFC dominant braking strategies were associated with faster $180^{\circ}$ COD performance $[57,58,88,94]$ and lower knee joint loads [57, 58, 88, 94]. During sharper COD, athletes will need to reduce their momentum to perform the COD $[57,95,138]$. Therefore, encouraging greater reductions in COM velocity over the PFC to lower the subsequent velocity at FFC (key determinant of greater knee joint loads), by facilitating effective PFC braking, could also lower knee joint loads while maintaining performance. It is worth noting that some athletes may not effectively adopt a PFC dominant braking strategy, so that they can maintain velocity and transfer it to the exit. This is problematic, however, because this results in higher COM FFC velocities which magnifies knee joint loads (Fig. 2). Thus, encouraging a PFC braking strategy appears to be a practical solution; however, practitioners should be conscious that athletes should be conditioned to be able to generate their own propulsive impulse and momentum during the push-off, so they are not solely reliant on initial momentum. Finally, smaller lateral trunk flexion angles and range of motion were largely associated with smaller GCTs, a critical determinant of faster performance $[50,51,53-55,58,59]$, while greater lateral trunk flexion angles have been shown to increase knee joint loads $[31,62,67]$. Previous research has shown that medial trunk lean towards the direction of travel was associated with faster performance [50, 53]. Consequently, practitioners should instruct cutting techniques with smaller lateral trunk flexion (trunk lean towards the intended cut) and range of motion for faster and safer performance.

Overall, mechanics associated with faster cutting performance are in direct conflict with mechanics for safer cutting. It is important to note that optimal performance and "high-risk" knee joint loading is not attributed solely to one variable, but the amalgamation and interaction of velocity, joint kinematics and kinetics, and braking and propulsive forces (Table 2). As such, practitioners must consider the performance and injury risk implications when coaching and modifying cutting techniques. In light of the finding that faster athletes generally display greater knee joint loads and are unlikely to sprint slower, it is imperative that athletes have the physical capacity (i.e. neuromuscular control, co-contraction, and rapid force production) and technique to tolerate the knee joint loading demands of side-steps [9, $29,33,62,133,139-141]$. It is likely that physically better conditioned athletes (faster athletes) approach faster potentially due to a "self-regulation" concept, whereby they know they have the physical capacity to tolerate the loads associated with high-velocity COD [57, 96], while better performers may also have the strength capacity to adopt favourable mechanics which contributes to superior cutting performance [56, 96].

Specifically, high levels of strength and activation of the hamstrings [140, 142, 143], gluteals [142, 144], soleus [142, 145], and trunk [72, 146] are needed to reduce non-contact ACL injury risk, support the multiplanar knee joint loads experienced during COD [141, 142, 147, 148], and assist in ligament unloading [141, 147]. This might be best achieved via a periodised multicomponent training programme which integrates strength, plyometric (jump-landing), balance, trunk control, and COD training [133, 149]. Moreover, given the importance of velocity for faster performance, it is integral that practitioners progressively expose athletes to cutting drills of higher velocity [101], and consider the athlete's training status and strength capacity when exposing them to high-velocity cutting drills $[5,9,18]$.

\section{Limitations}

It is worth noting that there were several limitations in the present study. First, males were only investigated, thus caution is advised regarding the generalisation of these results to female athletes and other athletic populations. Second, the biomechanical demands are angle dependent $[29,63$, 82 , 95, 138, 150-153]; thus, the findings of this study are applicable to pre-planned $90^{\circ}$ cuts only. Practitioners should, therefore, be cautious extrapolating these findings to agility tasks because subtle differences in cutting kinetics and 
kinematics have been observed between pre-planned and unplanned (generic stimuli) cutting [154, 155]. However, it is worth noting that the use of generic stimuli for the unplanned cutting tasks (i.e.., flashing light/arrow) have been criticised because they are not a sport-specific stimulus and lack ecological validity [10, 156, 157]. Further insight is required into biomechanical determinants of performance and surrogates of ACL injury risk in cuts and turns of different angles, actions, and unplanned tasks utilising a sportspecific stimulus. But, notwithstanding this limitation, the findings of this study provide a deeper understanding into the biomechanical demands of pre-planned COD, whereby COD speed provides the mechanical and physical basis for agility [5]. The fundamental biomechanical and movement principles should be similar between planned and unplanned cutting [9]; thus, improvements in the mechanical ability to change direction (i.e. fast mover) may theoretically, and speculatively, transfer to improved agility [5, 158, 159]. While from a motor skill learning perspective, the practice of pre-planned cutting is advocated before increasing intensity, complexity, and sports-specificity with the introduction of unanticipated cutting $[5,9,17,18]$. Further research is needed exploring the effect of COD speed training on agility performance.

Although a standardised surface was used, this surface does not reflect the grass and artificial field-turfs that the athletes regularly perform their CODs on. Additionally, the present study used a discrete data analysis approach, similar to that of previous work who inspected the relationship between cutting biomechanics and performance and surrogates of ACL injury risk [70, 81]; however, this approach can lead to regional focus bias and potentially valuable information is left unexamined [160, 161]. Therefore, for a deeper level of understanding, future research is necessary that considers the full temporal waveform for further insight into the biomechanical determinants of cutting performance and surrogates of ACL injury risk. Finally, it should be noted that the p-values for correlational analysis were not Bonferroni corrected which could increase type 1 error rate. However, Bonferroni correction is a controversial area which can also increase type 2 error rate, reduce statistical power, and can lead to publication bias, and arguably the magnitude is of greater importance [162, 163]; justifying the use of the $\geq 0.40$ threshold approach adopted in the present study as proposed by Welch et al. [51]. Nevertheless, retrospective correlational analysis of the data with Bonferroni correction ( $p$-value multiplied by number of correlations) confirmed that all variables with correlation values $\geq 0.40$ still satisfied statistical significance.

\section{Conclusion}

The results of this study confirm that techniques and mechanics associated with faster cutting performance (i.e. faster COM cutting velocities, greater FFC braking forces in short GCTs, greater KFMs, smaller hip and knee flexion, and greater internal foot progression angles) are in conflict with safer cutting mechanics (i.e. reduced knee joint loading) (Supplementary material 2, Fig. 2), and support the "performance-injury conflict" concept [78-81, 101]. Consequently, practitioners must be cautious when coaching and manipulating cutting technique and mechanics, and should acknowledge the implications of technique modification on performance and potential injury risk. Because athletes are driven by performance, techniques and mechanics that result in effective performance even at the expense of greater knee joint loading will inevitably be adopted and will also be a by-product of their sport. Therefore, practitioners should develop their athletes' physical capacity (i.e. neuromuscular control, co-contraction, and rapid force production) and technique to tolerate and support the knee joint loading demands of side-steps [9, 29, 33, 62, 133, 139-142]. Knee valgus is linked with greater knee joint loads with no associated performance benefits, while PFC braking dominant strategies and minimising lateral trunk flexion are factors associated with faster performance and safer COD mechanics. Therefore, coaching PFC dominant braking strategies and minimising knee valgus and lateral trunk flexion should facilitate effective performance and potentially reduce knee joint loading, thus potential ACL injury risk.

Supplementary Information The online version contains supplementary material available at https://doi.org/10.1007/s40279-021-01448-3.

Acknowledgements The authors would like to thank Laura Smith and Steve Horton for their assistance with data collection.

\section{Declarations}

Funding No sources of funding were used to assist in the preparation of this article.

Conflicts of interest Thomas Dos'Santos, Christopher Thomas, Alistair McBurnie, Paul Comfort, and Paul Jones declare that they have no conflicts of interest relevant to the content of this article.

Ethics approval This study was performed in accordance with the ethical standards of the Helsinki Declaration. The investigation was approved by the University of Salford Institutional Ethics Review Board (HSR1617-02).

Informed consent All participants provided informed consent.

Data availability The datasets used and/or analysed during the current study are available from the corresponding author on reasonable request. 
Author Contributions All authors contributed to the design, analysis, interpretation of data, and writing of the manuscript. TD, CT, and AM collected the data.

Open Access This article is licensed under a Creative Commons Attribution 4.0 International License, which permits use, sharing, adaptation, distribution and reproduction in any medium or format, as long as you give appropriate credit to the original author(s) and the source, provide a link to the Creative Commons licence, and indicate if changes were made. The images or other third party material in this article are included in the article's Creative Commons licence, unless indicated otherwise in a credit line to the material. If material is not included in the article's Creative Commons licence and your intended use is not permitted by statutory regulation or exceeds the permitted use, you will need to obtain permission directly from the copyright holder. To view a copy of this licence, visit http://creativecommons.org/licenses/by/4.0/.

\section{References}

1. Sweeting AJ, Aughey RJ, Cormack SJ, Morgan S. Discovering frequently recurring movement sequences in team-sport athlete spatiotemporal data. J Sports Sci. 2017;35(24):2439-45.

2. Sheppard JM, Dawes JJ, Jeffreys I, Spiteri T, Nimphius S. Broadening the view of agility: A scientific review of the literature. $\mathrm{J}$ Aust Strength Cond. 2014;22(3):6-25.

3. Young WB, Dawson B, Henry GJ. Agility and change-ofdirection speed are independent skills: Implications for training for agility in invasion sports. Int J Sports Sci Coach. 2015;10(1):159-69.

4. Robinson G, O'Donoghue P, Nielson P. Path changes and injury risk in English FA Premier League soccer. Int J Perf Anal Spor. 2011;11(1):40-56.

5. Nimphius S. Increasing agility. In: Joyce D, Lewindon D, editors. High-performance training for sports. Human Kinetics; 2014. p. 185-98.

6. Bloomfield J, Polman R, Donoghue P. Physical demands of different positions in FA Premier League soccer. J Sport Sci Med. 2007;6(1):63-70.

7. Faude O, Koch T, Meyer T. Straight sprinting is the most frequent action in goal situations in professional football. J Sports Sci. 2012;30(7):625-31.

8. Karcher C, Buchheit M. On-court demands of elite handball, with special reference to playing positions. Sports Med. 2014;44(6):797-814.

9. Nimphius S. Training change of direction and agility. In: Turner A, Comfort P, editors. Advanced strength and conditioning. Routledge; 2017. p. 291-308.

10. Nimphius S, Callaghan SJ, Bezodis NE, Lockie RG. Change of direction and agility tests: challenging our current measures of performance. Strength Cond J. 2017;40(1):26-38.

11. Nimphius S, Callaghan SJ, Sptieri T, Lockie RG. Change of direction deficit: a more isolated measure of change of direction performance than total 505 time. J Strength Cond Res. 2016;30:3024-32.

12. Fox AS, Spittle M, Otago L, Saunders N. Offensive agility techniques performed during international netball competition. Int $\mathbf{J}$ Sports Sci Coach. 2014;9(3):543-52.

13. Zahidi NNM, Ismail SI. Notational analysis of evasive agility skills executed by attacking ball carriers among elite rugby players of the 2015 Rugby World Cup. Movement Health Ex. 2018;7(1):99-113.

14. Wheeler KW, Askew CD, Sayers MG. Effective attacking strategies in rugby union. Eur J Sports Sci. 2010;10(4):237-42.
15. Sayers M, Washington-King J. Characteristics of effective ball carries in Super 12 rugby. Int J Perf Anal Spor. 2005;5(3):92-106.

16. Nedelec M, McCall A, Carling C, Legall F, Berthoin S, Dupont G. The influence of soccer playing actions on the recovery kinetics after a soccer match. J Strength Cond Res. 2014;28(6):1517-23.

17. Dos'Santos T, McBurnie A, Thomas C, Comfort P, Jones PA. Biomechanical comparison of cutting techniques: a review and practical applications. Strength Cond J. 2019;41(4):40-54.

18. DeWeese BH, Nimphius S. Program design technique for speed and agility training. In: Haff GG, Triplett NT, editors. Essentials of strength training and conditioning. Human Kinetics; 2016. p. 521-58.

19. Walden M, Krosshaug T, Bjorneboe J, Andersen TE, Faul O, Hagglund M. Three distinct mechanisms predominate in noncontact anterior cruciate ligament injuries in male professional football players: a systematic video analysis of 39 cases. Br J Sports Med. 2015;49(22):1452-60.

20. Olsen O-E, Myklebust G, Engebretsen L, Bahr R. Injury mechanisms for anterior cruciate ligament injuries in team handball a systematic video analysis. Am J Sport Med. 2004;32(4):1002-12.

21. Brophy RH, Stepan JG, Silvers HJ, Mandelbaum BR. Defending puts the anterior cruciate ligament at risk during soccer: a gender-based analysis. Sports health. 2015;7(3):244-9.

22. Cochrane JL, Lloyd DG, Buttfield A, Seward H, McGivern J. Characteristics of anterior cruciate ligament injuries in Australian football. J Sci Med Sport. 2007;10(2):96-104.

23. Montgomery C, Blackburn J, Withers D, Tierney G, Moran C, Simms C. Mechanisms of ACL injury in professional rugby union: a systematic video analysis of 36 cases. Br J Sports Med. 2018;52(15):944-1001.

24. Faude O, Junge A, Kindermann W, Dvorak J. Injuries in female soccer players a prospective study in the german national league. Am J Sport Med. 2005;33(11):1694-700.

25. Boden BP, Dean GS, Feagin JA, Garrett WE. Mechanisms of anterior cruciate ligament injury. Orthopedics. 2000;23(6):573-8.

26. Koga H, Nakamae A, Shima Y, Iwasa J, Myklebust G, Engebretsen $\mathrm{L}$, et al. Mechanisms for noncontact anterior cruciate ligament injuries knee joint kinematics in 10 injury situations from female team handball and basketball. Am J Sport Med. 2010;38(11):2218-25.

27. Johnston JT, Mandelbaum BR, Schub D, Rodeo SA, Matava MJ, Silvers HJ, et al. Video analysis of anterior cruciate ligament tears in professional American football athletes. Am J Sport Med. 2018;46(4):862-8.

28. Kimura Y, Ishibashi Y, Tsuda E, Yamamoto Y, Tsukada H, Toh $\mathrm{S}$. Mechanisms for anterior cruciate ligament injuries in badminton. Br J Sports Med. 2010;44(15):1124-7.

29. Besier TF, Lloyd DG, Cochrane JL, Ackland TR. External loading of the knee joint during running and cutting maneuvers. Med Sci Sports Exerc. 2001;33(7):1168-75.

30. Jones PA, Herrington L, Graham-Smith P. Braking characteristics during cutting and pivoting in female soccer players. J Electromyogr Kines. 2016;30:46-54.

31. Dempsey AR, Lloyd DG, Elliott BC, Steele JR, Munro BJ, Russo KA. The effect of technique change on knee loads during sidestep cutting. Med Sci Sports Exerc. 2007;39(10):1765-73.

32. Dempsey AR, Lloyd DG, Elliott BC, Steele JR, Munro BJ. Changing sidestep cutting technique reduces knee valgus loading. Am J Sport Med. 2009;37(11):2194-200.

33. Kristianslund E, Faul O, Bahr R, Myklebust G, Krosshaug T. Sidestep cutting technique and knee abduction loading: implications for ACL prevention exercises. Br J Sports Med. 2014;48(9):779-83. 
34. Shin CS, Chaudhari AM, Andriacchi TP. Valgus plus internal rotation moments increase anterior cruciate ligament strain more than either alone. Med Sci Sports Exerc. 2011;43(8):1484-91.

35. Markolf KL, Burchfield DM, Shapiro MM, Shepard MF, Finerman GAM, Slauterbeck JL. Combined knee loading states that generate high anterior cruciate ligament forces. J Orthop Res. 1995;13(6):930-5.

36. Kiapour AM, Demetropoulos CK, Kiapour A, Quatman CE, Wordeman SC, Goel VK, et al. Strain response of the anterior cruciate ligament to uniplanar and multiplanar loads during simulated landings: implications for injury mechanism. Am J Sport Med. 2016;44(8):2087-96.

37. Oh YK, Lipps DB, Ashton-Miller JA, Wojtys EM. What strains the anterior cruciate ligament during a pivot landing? Am J Sport Med. 2012;40(3):574-83.

38. Bates NA, Myer GD, Shearn JT, Hewett TE. Anterior cruciate ligament biomechanics during robotic and mechanical simulations of physiologic and clinical motion tasks: a systematic review and meta-analysis. Clin Biomech. 2015;30(1):1-13.

39. Hewett T. Preventive biomechanics: a paradigm shift with a translational approach to biomechanics. Am J Sports Med. 2017;45(11):2654-64.

40. Cumps E, Verhagen E, Annemans L, Meeusen R. Injury rate and socioeconomic costs resulting from sports injuries in Flanders: data derived from sports insurance statistics 2003. Br J Sports Med. 2008;42(9):767-72.

41. Quatman CE, Hewett TE. The anterior cruciate ligament injury controversy: is "valgus collapse" a sex-specific mechanism? $\mathrm{Br}$ J Sports Med. 2009;43(5):328-35.

42. Lohmander LS, Englund PM, Dahl LL, Roos EM. The long-term consequence of anterior cruciate ligament and meniscus injuries. Am J Sport Med. 2007;35(10):1756-69.

43. Langford JL, Webster KE, Feller JA. A prospective longitudinal study to assess psychological changes following anterior cruciate ligament reconstruction surgery. Br J Sports Med. 2009;43(5):377-8.

44. van Yperen DT, Reijman M, van Es EM, Bierma-Zeinstra SMA, Meuffels DE. Twenty-year follow-up study comparing operative versus nonoperative treatment of anterior cruciate ligament ruptures in high-level athletes. Am J Sport Med. 2018;46(5):1129-36.

45. Renström PA. Eight clinical conundrums relating to anterior cruciate ligament (ACL) injury in sport: recent evidence and a personal reflection. Br J Sports Med. 2013;47(6):367-72.

46. Ding DY, Zhang AL, Allen CR, Anderson AF, Cooper DE, Group M, et al. Subsequent Surgery after Revision Anterior Cruciate Ligament Reconstruction: Rates and Risk Factors from a Multicenter Cohort. Am J Sport Med. 2017;45(9):2068-76.

47. Montalvo AM, Schneider DK, Yut L, Webster KE, Beynnon B, Kocher MS, et al. "What's my risk of sustaining an ACL injury while playing sports?" A systematic review with meta-analysis. Br J Sports Med. 2019;53(19):1003-12.

48. Lai CCH, Ardern CL, Feller JA, Webster KE. Eighty-three per cent of elite athletes return to preinjury sport after anterior cruciate ligament reconstruction: a systematic review with meta-analysis of return to sport rates, graft rupture rates and performance outcomes. Br J Sports Med. 2018;52(2):128-38.

49. Mohtadi NG, Chan DS. Return to sport-specific performance after primary anterior cruciate ligament reconstruction: a systematic review. Am J Sport Med. 2018;46(13):3307-16.

50. Marshall BM, Franklyn-Miller AD, King EA, Moran KA, Strike S, Falvey A. Biomechanical factors associated with time to complete a change of direction cutting maneuver. J Strength Cond Res. 2014;28(10):2845-51.

51. Welch N, Richter C, Franklyn-Miller A, Moran K. Principal component analysis of the associations between kinetic variables in cutting and jumping, and cutting performance outcome. $\mathrm{J}$ Strength Cond Res. 2019. (Published ahead of print).

52. Weir G, Alderson J, Smailes N, Elliott B, Donnelly C. A reliable video-based ACL injury screening tool for female team sport athletes. Int J Sports Med. 2019;40(3):191-9.

53. Welch N, Richter C, Franklyn-Miller A, Moran K. Principal component analysis of the biomechanical factors associated with performance during cutting. J Strength Cond Res. 2019. (Published Ahead of Print).

54. Sasaki S, Nagano Y, Kaneko S, Sakurai T, Fukubayashi T. The relationship between performance and trunk movement during change of direction. J Sport Sci Med. 2011;10(1):112-8.

55. Spiteri T, Newton RU, Binetti M, Hart NH, Sheppard JM, Nimphius S. Mechanical determinants of faster change of direction and agility performance in female basketball athletes. J Strength Cond Res. 2015;28(3):2205-14.

56. Spiteri T, Cochrane JL, Hart NH, Haff GG, Nimphius S. Effect of strength on plant foot kinetics and kinematics during a change of direction task. Eur J Sports Sci. 2013;13(6):646-52.

57. Jones PA, Thomas C, Dos'Santos T, McMahon J, Graham-Smith P. The role of eccentric strength in $180^{\circ}$ turns in female soccer players. Sports. 2017;5(2):42.

58. Dos'Santos T, Thomas C, Jones PA, Comfort P. Mechanical determinants of faster change of direction speed performance in male athletes. J Strength Cond Res. 2017;31:696-705.

59. Maloney SJ, Richards J, Nixon DG, Harvey LJ, Fletcher IM. Do stiffness and asymmetries predict change of direction performance? J Sports Sci. 2016;35(6):547-56.

60. Dos'Santos T, McBurnie A, Thomas C, Comfort P, Jones PA. Biomechanical determinants of the modified and traditional 505 change of direction speed test. J Strength Cond Res. 2020;34(5):1285-96.

61. Jones PA, Herrington L, Graham-Smith P. Technique determinants of knee abduction moments during pivoting in female soccer players. Clin Biomech. 2016;31:107-12.

62. Jones PA, Herrington L, Graham-Smith P. Technique determinants of knee joint loads during cutting in female soccer players. Hum Mov Sci. 2015;42:203-11.

63. Sigward SM, Cesar GM, Havens KL. Predictors of frontal plane knee moments during side-step cutting to 45 and 110 degrees in men and women: implications for anterior cruciate ligament injury. Clin J Sport Med. 2015;25(6):529-34.

64. McLean SG, Huang X, van den Bogert AJ. Association between lower extremity posture at contact and peak knee valgus moment during sidestepping: implications for ACL injury. Clin Biomech. 2005;20(8):863-70.

65. David S, Komnik I, Peters M, Funken J, Potthast W. Identification and risk estimation of movement strategies during cutting maneuvers. J Sci Med Sport. 2017;20(12):1075-80.

66. Donnelly CJ, Chinnasee C, Weir G, Sasimontonkul S, Alderson J. Joint dynamics of rear-and fore-foot unplanned sidestepping. J Sci Med Sport. 2017;20(1):32-7.

67. Jamison ST, Pan X, Chaudhari AMW. Knee moments during runto-cut maneuvers are associated with lateral trunk positioning. J Biomech. 2012;45(11):1881-5.

68. Sigward SM, Powers CM. Loading characteristics of females exhibiting excessive valgus moments during cutting. Clin Biomech. 2007;22(7):827-33.

69. Yoshida N, Kunugi S, Mashimo S, Okuma Y, Masunari A, Miyazaki S, et al. Effect of forefoot strike on lower extremity muscle activity and knee joint angle during cutting in female team handball players. Sports Med-Open. 2016;2(1):32.

70. Havens KL, Sigward SM. Cutting mechanics: relation to performance and anterior cruciate ligament injury risk. Med Sci Sports Exerc. 2015;47(4):818-24. 
71. Frank B, Bell DR, Norcross MF, Blackburn JT, Goerger BM, Padua DA. Trunk and hip biomechanics influence anterior cruciate loading mechanisms in physically active participants. Am J Sport Med. 2013;41(11):2676-83.

72. Donnelly CJ, Lloyd DG, Elliott BC, Reinbolt JA. Optimizing whole-body kinematics to minimize valgus knee loading during sidestepping: implications for ACL injury risk. J Biomech. 2012;45(8):1491-7.

73. Celebrini RG, Eng JJ, Miller WC, Ekegren CL, Johnston JD, MacIntyre DL. The effect of a novel movement strategy in decreasing ACL risk factors in female adolescent soccer players. J Strength Cond Res. 2012;26(12):3406-17.

74. Markolf KL, Gorek JF, Kabo JM, Shapiro MS. Direct measurement of resultant forces in the anterior cruciate ligament. An in vitro study performed with a new experimental technique. J Bone Jt Surg Am. 1990;72(4):557-67.

75. Shin CS, Chaudhari AM, Andriacchi TP. The effect of isolated valgus moments on ACL strain during single-leg landing: a simulation study. J Biomech. 2009;42(3):280-5.

76. Withrow TJ, Huston LJ, Wojtys EM, Ashton-Miller JA. The effect of an impulsive knee valgus moment on in vitro relative ACL strain during a simulated jump landing. Clin Biomech. 2006;21(9):977-83.

77. Hewett T, Myer GD, Ford KR, Heidt RS, Colosimo AJ, McLean $\mathrm{SG}$, et al. Biomechanical measures of neuromuscular control and valgus loading of the knee predict anterior cruciate ligament injury risk in female athletes a prospective study. Am J Sport Med. 2005;33(4):492-501.

78. Fox AS. Change-of-direction biomechanics: is what's best for anterior cruciate ligament injury prevention also best for performance? Sports Med. 2018;48(8):1799-807.

79. Sankey SP, Robinson MA, Vanrenterghem J. Whole-body dynamic stability in side cutting: implications for markers of lower limb injury risk and change of direction performance. $\mathrm{J}$ Biomech. 2020; 109711.

80. Dai B, William EG, Michael TG, Darin AP, Robin MQ, Bing Y. The effects of 2 landing techniques on knee kinematics, kinetics, and performance during stop-jump and side-cutting tasks. Am J Sport Med. 2014;43(2):466-74.

81. McBurnie A, Dos' Santos T, Jones PA. biomechanical associates of performance and knee joint loads during an $70-90^{\circ}$ cutting maneuver in sub-elite soccer players. J Strength Cond Res. 2019. (Published Ahead of print).

82. Havens KL, Sigward SM. Joint and segmental mechanics differ between cutting maneuvers in skilled athletes. Gait Posture. 2015;41(1):33-8.

83. Withrow TJ, Huston LJ, Wojtys EM, Ashton-Miller JA. The relationship between quadriceps muscle force, knee flexion, and anterior cruciate ligament strain in an in vitro simulated jump landing. Am J Sport Med. 2006;34(2):269-74

84. Beynnon BD, Fleming BC, Johnson RJ, Nichols CE, Renström PA, Pope MH. Anterior cruciate ligament strain behavior during rehabilitation exercises in vivo. Am J Sport Med. 1995;23(1):24-34.

85. Beynnon B, Howe J, Pope MH, Johnson RJ, Fleming B. The measurement of anterior cruciate ligament strain in vivo. Int Orthop. 1992;16(1):1-12.

86. Markolf KL, O’Neill G, Jackson SR, McAllister DR. Effects of applied quadriceps and hamstrings muscle loads on forces in the anterior and posterior cruciate ligaments. Am J Sport Med. 2004;32(5):1144-9.

87. Sell TC, Ferris CM, Abt JP, Tsai YS, Myers JB, Fu FH, et al. Predictors of proximal tibia anterior shear force during a vertical stop-jump. J Orthop Res. 2007;25(12):1589-97.
88. Graham-Smith P, Atkinson L, Barlow R, Jones P. Braking characteristics and load distribution in 180 degree turns. In: Proceedings of the 5th annual UKSCA conference; 2009; 2009.

89. Yu B, Lin C-F, Garrett WE. Lower extremity biomechanics during the landing of a stop-jump task. Clin Biomech. 2006;21(3):297-305.

90. Holding R, Meir R. Applying biomechanical research to coaching instruction of stepping movements in rugby football. Strength Cond J. 2014;36(3):8-12.

91. Brault S, Bideau B, Kulpa R, Craig CM. Detecting deception in movement: the case of the side-step in rugby. PLoS ONE. 2012;7(6):e37494.

92. Brault SB, Bideau B, Craig C, Kulpa R. Balancing deceit and disguise: How to successfully fool the defender in a 1 vs. 1 situation in rugby. Hum Mov Sci. 2010;29(3):412-25.

93. Inaba Y, Yoshioka S, Iida Y, Hay DC, Fukashiro S. A biomechanical study of side steps at different distances. J Appl Biomech. 2013;29(3):336-45.

94. Dos'Santos T, Thomas C, Comfort P, Jones PA. The role of the penultimate foot contact during change of direction: implications on performance and risk of injury. Strength Cond J. 2019;41(1):87-104.

95. Hader K, Palazzi D, Buchheit M. Change of direction speed in soccer: how much braking is enough? Kineziologija. 2015;47(1):67-74.

96. Jones PA, Dos' Santos T, McMahon JJ, Graham-Smith P. Contribution of eccentric strength to cutting performance in female soccer players. J Strength Cond Res. 2019. (Published ahead of print)

97. Vanrenterghem J, Venables E, Pataky T, Robinson MA. The effect of running speed on knee mechanical loading in females during side cutting. J Biomech. 2012;45(14):2444-9.

98. Nedergaard NJ, Kersting U, Lake M. Using accelerometry to quantify deceleration during a high-intensity soccer turning manoeuvre. J Sports Sci. 2014;32(20):1897-905.

99. Dai B, Garrett WE, Gross MT, Padua DA, Queen RM, Yu B. The effect of performance demands on lower extremity biomechanics during landing and cutting tasks. J Sport Health Sci. 2016;43(9):1680-708.

100. Kimura K, Sakurai S. A sidestep cut preparation strategy decreases the external load applied to the knee joint. Int J Sport Health Sci. 2013;11:109-17.

101. Dos'Santos T, Thomas C, Comfort P, Jones PA. The effect of angle and velocity on change of direction biomechanics: an angle-velocity trade-off. Sports Med. 2018;48(10):2235-53.

102. Granero-Gil P, Bastida-Castillo A, Rojas-Valverde D, GómezCarmona CD, de la Cruz SE, Pino-Ortega J. Influence of contextual variables in the changes of direction and centripetal force generated during an elite-level soccer team season. Int J Environ Res Public Health. 2020;17(3):967.

103. Ato M, López-García JJ, Benavente A. A classification system for research designs in psychology. Anales de Psicología/Ann Psychol. 2013;29(3):1038-59.

104. Dos'Santos T, Comfort P, Jones PA. Average of trial peaks versus peak of average profile: impact on change of direction biomechanics. Sport Biomech. 2020;19(4):483-92.

105. Dos'Santos T, McBurnie A, Donelon T, Thomas C, Comfort P, Jones PA. A qualitative screening tool to identify athletes with "high-risk" movement mechanics during cutting: The cutting movement assessment score (CMAS). Phys Ther Sport. 2019;38:152-61.

106. Faul F, Erdfelder E, Buchner A, Lang A-G. Statistical power analyses using $\mathrm{G}^{*}$ Power 3.1: tests for correlation and regression analyses. Behav Res Methods. 2009;41(4):1149-60.

107. Jones PA, Donelon T, Dos' ST. A preliminary investigation into a qualitative assessment tool to identify athletes with high knee 
abduction moments during cutting: Cutting Movement Assessment Score (CMAS). Prof Strength Cond. 2017;47:37-42.

108. Winter DA. Biomechanics and motor control of human movement. Wiley; 2009.

109. Roewer BD, Ford KR, Myer GD, Hewett TE. The "impact" of force filtering cut-off frequency on the peak knee abduction moment during landing: artefact or "artifiction"? Br J Sports Med. 2014;48(6):464-8.

110. Dos'Santos T, Comfort P, Jones PA. Effect of low pass filtering cut-off frequencies on knee abduction moments during cutting. In: BASES Biomechanics Interest Group; 2018 4/4/2018; University of Salford, UK; 2018.

111. Winter DA. Biomechanics and motor control of human motion. New York: Wiley-Interscience; 1990.

112. Hopkins WG. A scale of magnitudes for effect statistics. A new view of statistics. 2002:Retrieved from http://sportsci.org/resou rce/stats/effectmag.html.

113. Vincent WJ, Weir JP. Statistics in kinesiology: Human Kinetics; 2012.

114. Dames KD, Smith JD, Heise GD. Averaging trials versus averaging trial peaks: impact on study outcomes. J Appl Biomech. 2017;33(3):233-6.

115. Bourgeois F, McGuigan MR, Gill ND, Gamble G. Physical characteristics and performance in change of direction tasks: a brief review and training considerations. J Aust Strength Cond. 2017;25(5):104-17.

116. Zatsiorsky VM, Kraemer WJ. Science and practice of strength training: Human Kinet. 2006: p. 21.

117. Andrews JR, McLeod WD, Ward T, Howard K. The cutting mechanism. Am J Sport Med. 1977;5(3):111-21.

118. Rovan K, Kugovnik O, Holmberg LJ, Supej M. The steps needed to perform acceleration and turning at different approach speeds. Kinesiol Slov. 2014;20(1):38-50.

119. Patla AE, Adkin A, Ballard T. Online steering: coordination and control of body center of mass, head and body reorientation. Exp Br Res. 1999;129(4):629-34.

120. David S, Mundt M, Komnik I, Potthast W. Understanding cutting maneuvers - the mechanical consequence of preparatory strategies and foot strike pattern. Hum Mov Sci. 2018;62:202-10.

121. Bosco C, Komi PV, Ito A. Prestretch potentiation of human skeletal muscle during ballistic movement. Acta Physiol Scand. 1981;111(2):135-40.

122. Latash ML, Zatsiorsky VM. Joint stiffness: Myth or reality? Hum Mov Sci. 1993;12(6):653-92.

123. Devita P, Skelly WA. Effect of landing stiffness on joint kinetics and energetics in the lower extremity. Med Sci Sports Exerc. 1992;24(1):108-15.

124. Leppänen M, Pasanen K, Kujala UM, Vasankari T, Kannus P, Äyrämö S, et al. Stiff landings are associated with increased ACL injury risk in young female basketball and floorball players. Am J Sport Med. 2017;45(2):386-93.

125. Zhang S-N, Bates BT, Dufek JS. Contributions of lower extremity joints to energy dissipation during landings. Med Sci Sports Exerc. 2000;32(4):812-9.

126. Shimokochi Y, Ambegaonkar JP, Meyer EG, Lee SY, Shultz SJ. Changing sagittal plane body position during single-leg landings influences the risk of non-contact anterior cruciate ligament injury. Knee Surg Sports Traumatol Arthrosc. 2013;21(4):888-97.

127. Yeow $\mathrm{CH}$, Lee PVS, Goh JCH. Non-linear flexion relationships of the knee with the hip and ankle, and their relative postures during landing. Knee. 2011;18(5):323-8.

128. Sigward SM, Pollard CD. Proximal risk factors for ACL injury: role of the hip joint and musculature. In: ACL Injuries in the female athlete. Springer; 2018. p. 207-23.
129. Celebrini RG, Eng JJ, Miller WC, Ekegren CL, Johnston JD, Depew TA, et al. The effect of a novel movement strategy in decreasing ACL risk factors in female adolescent soccer players: a randomized controlled trial. Clin J Sport Med. 2014;24(2):134-41.

130. Pollard CD, Sigward SM, Powers CM. Limited hip and knee flexion during landing is associated with increased frontal plane knee motion and moments. Clin Biomech. 2010;25(2):142-6.

131. Nguyen A-D, Taylor JB, Wimbish TG, Keith JL, Ford KR. Preferred hip strategy during landing reduces knee abduction moment in collegiate female soccer players. J Sport Rehabil. 2018;27(3):213-7.

132. Hewett TE, Stroupe AL, Nance TA, Noyes FR. Plyometric training in female athletes: decreased impact forces and increased hamstring torques. Am J Sport Med. 1996;24(6):765-73.

133. Padua DA, DiStefano LJ, Hewett TE, Garrett WE, Marshall SW, Golden GM, et al. National Athletic Trainers' Association Position Statement: prevention of anterior cruciate ligament injury. $j$ Athl Train. 2018;53:5-19.

134. Herrington LC, Comfort P. Training for prevention of ACL injury: Incorporation of progressive landing skill challenges into a program. Strength Cond J. 2013;35(6):59-65.

135. Koga H, Muneta T, Bahr R, Engebretsen L, Krosshaug T. ACL injury mechanisms: lessons learned from video analysis. Rotatory knee instability. Springer; 2017. p. 27-36.

136. Hashemi J, Breighner R, Chandrashekar N, Hardy DM, Chaudhari AM, Shultz SJ, et al. Hip extension, knee flexion paradox: a new mechanism for non-contact ACL injury. J Biomech. 2011;44(4):577-85.

137. McLean SG, Lipfert SW, Van den Bogert AJ. Effect of gender and defensive opponent on the biomechanics of sidestep cutting. Med Sci Sports Exerc. 2004;36(6):1008-16.

138. Havens KL, Sigward SM. Whole body mechanics differ among running and cutting maneuvers in skilled athletes. Gait Posture. 2014;42(3):240-5

139. Suchomel TJ, Nimphius S, Stone MH. The importance of muscular strength in athletic performance. Sports Med. 2016;46(10):1419-49.

140. Weinhandl JT, Earl-Boehm JE, Ebersole KT, Huddleston WE, Armstrong BS, O'connor KM. Reduced hamstring strength increases anterior cruciate ligament loading during anticipated sidestep cutting. Clin Biomech. 2014;29(7):752-9.

141. Lloyd DG, Buchanan TS. Strategies of muscular support of varus and valgus isometric loads at the human knee. J Biomech. 2001;34(10):1257-67.

142. Maniar N, Schache AG, Sritharan P, Opar DA. Non-knee-spanning muscles contribute to tibiofemoral shear as well as valgus and rotational joint reaction moments during unanticipated sidestep cutting. Sci Rep. 2018;8(1):2501.

143. Serpell BG, Scarvell JM, Pickering MR, Ball NB, Newman P, Perriman D, et al. Medial and lateral hamstrings and quadriceps co-activation affects knee joint kinematics and ACL elongation: a pilot study. BMC Musculoskelet Disord. 2015;16(1):348.

144. Khayambashi K, Ghoddosi N, Straub RK, Powers CM. Hip muscle strength predicts noncontact anterior cruciate ligament injury in male and female athletes: a prospective study. Am J Sport Med. 2016;44(2):355-61.

145. Adouni M, Shirazi-Adl A, Marouane H. Role of gastrocnemius activation in knee joint biomechanics: gastrocnemius acts as an ACL antagonist. Comput Methods Biomech Biomed Engin. 2016;19(4):376-85.

146. Zazulak BT, Hewett TE, Reeves NP, Goldberg B, Cholewicki J. Deficits in neuromuscular control of the trunk predict knee injury risk: prospective biomechanical-epidemiologic study. Am J Sport Med. 2007;35(7):1123-30. 
147. Donnelly C, Elliott BC, Ackland TR, Doyle TL, Beiser TF, Finch CF, et al. An anterior cruciate ligament injury prevention framework: incorporating the recent evidence. Res Sports Med. 2012;20(3-4):239-62.

148. Maniar N, Schache AG, Cole MH, Opar DA. Lower-limb muscle function during sidestep cutting. J Biomech. 2019;82:186-92.

149. Dos'Santos T, Thomas C, Comfort P, Jones PA. The effect of training interventions on change of direction biomechanics associated with increased anterior cruciate ligament loading: a scoping review. Sports Med. 2019;49(12):1837-59.

150. Schot P, Dart J, Schuh M. Biomechanical analysis of two changeof-direction maneuvers while running. J Orthop Sports Phys Ther. 1995;22(6):254-8.

151. Schreurs MJ, Benjaminse A, Lemmink KA. Sharper angle, higher risk? The effect of cutting angle on knee mechanics in invasion sport athletes. J Biomech. 2017;63:144-50.

152. Hader K, Mendez-Villanueva A, Palazzi D, Ahmaidi S, Buchheit M. Metabolic power requirement of change of direction speed in young soccer players: not all is what it seems. PLoS ONE. 2016;11(3):e0149839.

153. Cortes N, Onate J, Van Lunen B. Pivot task increases knee frontal plane loading compared with sidestep and drop-jump. J Sports Sci. 2011;29(1):83-92.

154. Brown SR, Brughelli M, Hume PA. Knee mechanics during planned and unplanned sidestepping: a systematic review and meta-analysis. Sports Med. 2014;44(11):1573-88.
155. Almonroeder TG, Garcia E, Kurt M. The effects of anticipation on the mechanics of the knee during single leg cutting tasks: a systematic review. Int J Sports Phys Ther. 2015;10(7):918.

156. Young W, Farrow D. The importance of a sport-specific stimulus for training agility. Strength Cond J. 2013;35(2):39-43.

157. Paul DJ, Gabbett TJ, Nassis GP. Agility in team sports: Testing, training and factors affecting performance. Sports Med. 2016;46(3):421-42.

158. Gabbett TJ, Kelly JN, Sheppard JM. Speed, change of direction speed, and reactive agility of rugby league players. J Strength Cond Res. 2008;22(1):174-81.

159. Gabbett TJ, Sheppard JM. Testing and training agility. In: Tanner R, Gore C, editors. Physiological tests for elite athletes. 2nd ed. Human Kinetics; 2013. p. 199-205.

160. Preatoni E, Hamill J, Harrison AJ, Hayes K, Van Emmerik REA, Wilson C, et al. Movement variability and skills monitoring in sports. Sport Biomech. 2013;12(2):69-92.

161. Brown C, Bowser B, Simpson KJ. Movement variability during single leg jump landings in individuals with and without chronic ankle instability. Clin Biomech. 2012;27(1):52-63.

162. Armstrong RA. When to use the Bonferroni correction. Ophthalmic Physiol Opt. 2014;34(5):502-8.

163. Nakagawa S. A farewell to Bonferroni: the problems of low statistical power and publication bias. Behav Ecol. 2004;15(6):1044-5.

\section{Authors and Affiliations}

\section{Thomas Dos'Santos ${ }^{1,2} \circledast$ Christopher Thomas $^{2} \cdot$ Alistair McBurnie $^{3} \cdot$ Paul Comfort $^{2} \cdot$ Paul A. Jones $^{2}$}

1 Department of Sport and Exercise Sciences, Musculoskeletal Science and Sports Medicine Research Centre, Manchester Metropolitan University, All Saints Building, Manchester Campus John Dalton Building, Manchester Campus, Manchester M15 6BH, UK
2 Human Performance Laboratory, Directorate of Sport, Exercise, and Physiotherapy, University of Salford, Salford, Greater Manchester, UK

3 Manchester United Football Club, Manchester, UK 